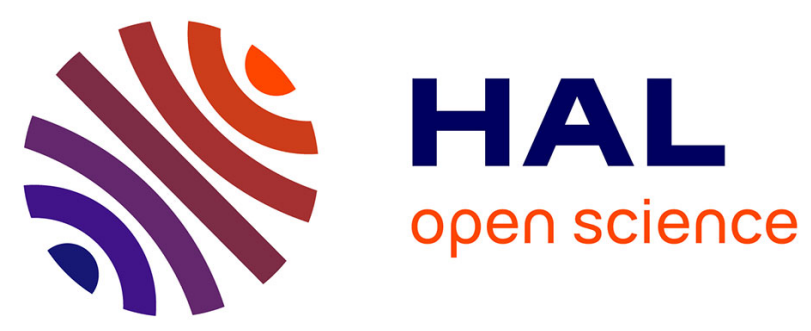

\title{
Distance from the sea as a driving force of microbial communities under water potential stresses in litters of two typical Mediterranean plant species
}

\author{
Anne Marie Farnet da Silva, Nathalie Boukhdoud, Raphaël Gros
}

\section{- To cite this version:}

Anne Marie Farnet da Silva, Nathalie Boukhdoud, Raphaël Gros. Distance from the sea as a driving force of microbial communities under water potential stresses in litters of two typical Mediterranean plant species. Geoderma, 2016, 269, pp.1-9. 10.1016/j.geoderma.2016.01.017 . hal-02068527

\section{HAL Id: hal-02068527 \\ https://hal.science/hal-02068527}

Submitted on 15 Mar 2019

HAL is a multi-disciplinary open access archive for the deposit and dissemination of scientific research documents, whether they are published or not. The documents may come from teaching and research institutions in France or abroad, or from public or private research centers.
L'archive ouverte pluridisciplinaire HAL, est destinée au dépôt et à la diffusion de documents scientifiques de niveau recherche, publiés ou non, émanant des établissements d'enseignement et de recherche français ou étrangers, des laboratoires publics ou privés. 


\title{
Distance from the sea as a driving force of microbial communities under water potential stresses in litters of two typical Mediterranean plant species
}

\author{
Anne Marie Farnet Da Silva *, Nathalie Boukhdoud, Raphaël Gros

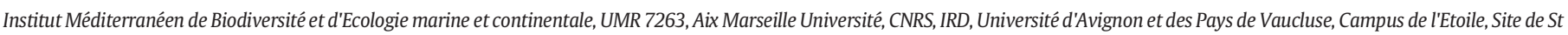 \\ Jérôme, 13397 Marseille Cedex 20, France
}

\begin{abstract}
A B S T R A C T
Though many studies have focused on the incidence of drought, little attention has been paid to osmotic stress and to how the interaction of the two stresses impacts microbial functioning. Moreover, deciphering how certain environmental factors such as distance from the sea or type of litter may shape microbial responses to these stresses is of huge importance. The objective of this study is to shed light on the impact of matric and osmotic stresses (combined or not) on litter microbial communities potentially shaped differently by either plant species or distance from the sea. Two Mediterranean plant species, Cistus albidus L. and Pistacia lentiscus L., collected from both inland and coastal areas, were used to set up a total of 72 mesocosms ( 4 mesocosms $\times 3$ types of litters (pure or mixed) $\times 2$ sites (coastal and inland) $\times 3$ types of stress). A first set of twenty four mesocosms 'control' ( 4 mesocosms $\times 3$ types of litters (pure or mixed) $\times 2$ sites (coastal and inland)) were maintained under favourable conditions for 60 days $\left(25^{\circ} \mathrm{C}, 600 \mathrm{~g} \cdot \mathrm{kg}^{-1}\right.$ water content). For matric stress, twenty four mesocosms were subjected to 5 drying/rewetting cycles ( 7 days at $25^{\circ} \mathrm{C} / 7$ days at $600 \mathrm{~g} \cdot \mathrm{kg}^{-1}$ water content and $25^{\circ} \mathrm{C}$ ). For osmotic stress, twenty four mesocosms received $10 \mathrm{mg}$ of chlorine ions per $\mathrm{g}$ of litter using $\mathrm{NaCl}$ and then were incubated at $600 \mathrm{~g} \cdot \mathrm{kg}^{-1}$ water content and $25^{\circ} \mathrm{C}$ for 60 days. The last twenty four mesocosms were subjected to the combined drought and salt stresses for 60 days. Resistance to added osmotic stress was also tested. Catabolic diversity assessed via Biolog Ecoplates, was higher in coastal than in inland areas after drought and combined stresses. Moreover, catabolic profiles were shaped differently after stresses depending on the litter type. Basal respiration withstood an added severe drought stress better in microbial communities previously subjected to combined stresses. Resistance to an added osmotic stress was higher in inland litters previously subjected to salt stress. Microbial communities from the coastal area were more able to maintain their catabolic potential and thus to withstand these stresses. Combined stresses and osmotic stress reinforced resistance to added severe drought or osmotic stress respectively. Thus our findings reveal that microbial communities previously subjected to water potential stresses were more capable to overcome additional stresses of similar nature, suggesting adaptation mechanisms to such type of stresses.
\end{abstract}

\section{Introduction}

Organic matter turnover is a crucial ecological process mainly realized by microbial communities via the exocellular enzymes they produce. Litter functioning is driven by various biotic and abiotic factors such as pedoclimatic conditions and nutrient quantity and quality, which are known to strongly determine the composition and structure of microbial communities (Coûteaux et al., 1995; Hättenschwiler et al., 2005). In the Mediterranean region, environmental conditions are particularly extreme. Soils are poor in organic matter, litters contain large quantities of recalcitrant phenolic compounds and the climate is characterized

\footnotetext{
* Corresponding author.

E-mail address: anne-marie.farnet@imbe.fr (A.M. Farnet Da Silva).
}

by severe summer drought (Pons and Quézel, 1998). Moreover, in coastal environments, such stresses are reinforced by the wind regime, which exacerbates desiccation, as well as more intense sunlight. Additional stresses, such as osmotic stress due to sea spray exposure, can also impact litter functioning (Qasemian et al., 2014). However, while many studies have examined litter functioning in inland areas under a Mediterranean climate (Fioretto et al., 2007, 2009; Papa et al., 2008), few have investigated whether microbial communities in coastal environments may be even more weakened by these additional and intensified pressures. Moreover, little is known about how the high salt concentrations in these environments may shape microbial communities and their tolerance to osmotic stresses (Rath and Rousk, 2015).

Both matric and osmotic stresses strongly influence microbial communities and their activities (Berard et al., 2011; Sardans and 
Penuelas, 2005; Sardinha et al., 2003) by drastically reducing water availability. This limits microbial growth, enzyme production and can even modify the protein conformation of enzymes (Wehtje et al., 1997). The impact of drying and rewetting events on litter microbial activities has been investigated extensively. The general conclusion is of a priming effect linked to the mineralization of labile carbon from cell lysis, aggregate breakdown or changes in microbial community structure (Borken and Matzner, 2009; Kakumanu et al., 2013). When the frequency of such events increases, these flushes of microbial activities decrease because of rarefaction of labile carbon amount and a specialization of microbial communities less sensitive to matric stress, with a constant microbial biomass and a low-level respiration rate (Butterly et al., 2009; Fierer et al., 2003). Microbial adaptation to osmotic stress is also observed with accumulation of osmolytes inside the cell (Kakumanu and Williams, 2014), which prevents cell lysis, but which is an energy-consuming process (Schimel et al., 2007). The recent studies of Chowdhury and Marschner (2011), Chowdhury et al. (2011a,b) have taken the first steps towards providing information about soil responses to both osmotic and matric stresses, suggesting a threshold of tolerance to decreasing water potential in the physiological mechanisms underlying microbial adaptation. However, the combination of such stresses typical of coastal environments and their effect on microbial functioning, have not yet been thoroughly evaluated.

We hypothesise here i) that litter microbial communities selected by coastal area conditions may be better resistant to water potential stresses than those from inland areas and ii) that different types of litter (i.e. different organic matter quality and quantity) may also influence the diversity of microbial communities and thus their tolerance of these stresses (Yuste et al., 2011). For instance, availability of nutrients, and recalcitrance of organic matter are supposed to strongly modify microbial diversity or the balance between bacteria and fungi, which are known to exhibit various tolerances to matric stresses. To test these hypotheses, we selected two Mediterranean plant species, Cistus albidus L. and Pistacia lentiscus L., collected both from inland and from coastal areas. Mesocosms were set up for each litter and for a mixture (50/50) of the plant species under study. These mesocosms were then subjected to drought, salt or combined stresses, mimicking conditions recorded in the coastal sampling area (Qasemian et al., 2014). Resistance to added osmotic stress or severe drying and rewetting events was also tested. Our objectives were i) to compare the responses of litter microbial communities to salt, drought or combined stresses found in coastal areas, ii) to determine the influence of type of litter (C. albidus L. vs P. lentiscus L.) and of distance from the sea (inland vs coastal litters) on microbial responses to stresses, iii) to test whether pre-exposure to stresses selected microbial communities more adapted to added osmotic stress and severe drying and rewetting events.

\section{Materials and methods}

\subsection{Site description and litter sampling}

Six sampling sites were chosen in the peri-urban area of Marseille on the French Mediterranean coast $\left(43^{\circ} 12^{\prime} 38.80^{\prime \prime} \mathrm{N} ; 5^{\circ} 21^{\prime} 19.53^{\prime \prime} \mathrm{E}\right)$. They included three coastal sites and three inland sites located respectively $30 \mathrm{~m}$ and $6 \mathrm{~km}$ from the sea (Qasemian et al., 2014). The distance between sites, whether coastal or inland, is $2 \mathrm{~km}$ at least, far exceeding the spatial dependence of most microbiological properties in soil (Nannipieri et al., 2003). The climate is Mediterranean, with a mean annual precipitation of $520 \mathrm{~mm}$ and mean monthly temperatures ranging from $7.2^{\circ} \mathrm{C}$ in January to $24.8^{\circ} \mathrm{C}$ in June. These sites $(25-230 \mathrm{~m}$ in elevation) present similar exposure (South), slope (10-15\%) and soil type (Calcaric Leptosol according to IUSS Working Group WRB, 2006). Shrub canopy cover is about $80 \%$ and characterized by Quercus coccifera, C. albidus, Cistus salvifolius, Rosmarinus officinalis, P. lentiscus, Rhammus alaternus, Asparagus acutifolius and Phillyrea angustifolia.
At each site, composite sampling was performed in November 2011 from litter (horizon Ol) of P. lentiscus and C. albidus. P. lentiscus is a thermophilic evergreen shrub, with sclerophyllous leaves, native throughout the Mediterranean region since it is highly tolerant to poor calcareous soils and to severe drought and is particularly widespread in seaside stony areas (García-Fayos and Verdú, 1998). C. albidus is a pioneer semi-deciduous shrub with haired leaves, also widely found in xeric Mediterranean soils (Oliveira and Peñuelas, 2000). C. albidus and $P$. lentiscus are the two dominant shrub species both in the coastal and inland areas under study. For each species, twenty samples of litter were randomly collected over a $1000 \mathrm{~m}^{2}$ area to obtain a composite sample. Contaminating debris (e.g. leaves of other species, including branches and seeds) were removed carefully from each collection. The samples were homogenized and stored in polyethylene bags at $4{ }^{\circ} \mathrm{C}$ until mesocosm preparation.

\subsection{Mesocosm preparation and experimental set-up}

Litter was placed in horticulture pots $(10 \times 10 \times 10 \mathrm{~cm})$ containing either $30 \mathrm{~g}$ (dry weight, DW) of Cistus litter, Pistacia litter or of a mixed Cistus-Pistacia litter (50/50, DW/DW) per mesocosm. A total of 72 mesocosms were prepared (4 mesocosms $\times 3$ types of litter $\times 2$ sites (coastal and inland) $\times 3$ types of stress). Litter was rehydrated to $600 \mathrm{~g} \cdot \mathrm{kg}^{-1}$ water content with deionized and sterilized water and the mesocosms were covered with pierced tin foil. The 72 mesocosms were pre-incubated for 30 days under temperature $\left(25^{\circ} \mathrm{C}\right)$ and water content $\left(600 \mathrm{~g} \cdot \mathrm{kg}^{-1}\right)$ conditions favourable to microbial growth. $600 \mathrm{~g} \cdot \mathrm{kg}^{-1}$ water content was chosen since this was the maximum water content recorded in litter in the field over a one year period in the coastal areas where samplings were performed (Qasemian et al., 2014). After this period of pre-incubation, a first set of twenty four mesocosms 'control' ( 4 mesocosms $\times 3$ types of litters (pure or mixed) $\times 2$ sites (coastal and inland)) were maintained under favourable conditions for 60 days $\left(25^{\circ} \mathrm{C}, 600 \mathrm{~g} \cdot \mathrm{kg}^{-1}\right.$ water content). A second set of twenty four mesocosms (drought stress) were subjected to 5 drying/rewetting cycles. Each drying/rewetting cycle was composed of 2 steps: i) a drying period of 7 days at $25^{\circ} \mathrm{C}$ to reach a final water content close to $150 \mathrm{~g} \cdot \mathrm{kg}^{-1} \mathrm{ii}$ ) a quick rewetting to recover $600 \mathrm{~g} \cdot \mathrm{kg}^{-1}$ water content followed by an incubation period for 7 days at $600 \mathrm{~g} \cdot \mathrm{kg}^{-1}$ water content and $25{ }^{\circ} \mathrm{C}$. A third set of twenty four mesocosms (osmotic stress) received $10 \mathrm{mg}$ of chlorine ions per $\mathrm{g}$ of litter using $\mathrm{NaCl}\left(\mathrm{EC}\right.$ of $1400 \mu \mathrm{S} \cdot \mathrm{cm}^{-1}$ ), which is the higher concentration found over a one-year monitoring in the coastal areas where samplings were performed as described by Qasemian et al. (2014). Then these mesocosms were incubated under the favourable conditions described above for 60 days. The last twenty four mesocosms were subjected to the combined drought and salt stresses for 60 days. A preliminary experiment showed that the same level of water potential stress assessed via water activity, $a_{w}$, (measured with Hygropalm probe, Rotronic, Fisher Scientific, Illkirch, France) was achieved: for matric stress, when $150 \mathrm{~g} \cdot \mathrm{kg}^{-1}$ water content was reached and for osmotic stress, after $\mathrm{NaCl}$ addition to litter at $600 \mathrm{~g} \cdot \mathrm{kg}^{-1}$ water content, a similar $a_{w}$ value of 0.8 was obtained. For combined stresses, $a_{w}$ was measured after $\mathrm{NaCl}$ addition to litter at $150 \mathrm{~g} \cdot \mathrm{kg}^{-1}$ water content and a value of 0.7 was obtained. Thermodynamic water activity is defined as the ratio of water vapour pressure in the system over pure water that at constant pressure and temperature.

After incubation time, a fraction of each sample was dried and ground prior to chemical analysis and all the experiments involving microbial markers started immediately and were performed over one week.

\subsection{Plant litter chemical traits}

The chemical composition of Cistus and Pistacia litters collected in coastal and inland sites and used in the mesocosm-scale experiment 
was determined as follows: as a preliminary, litters were characterized for moisture and electrical conductivity (EC). Total organic carbon (TOC) and nitrogen $(\mathrm{N})$ contents were determined by combustion in an Elemental Analyzer (Flash EA 1112 series ThermoScientific). Polyphenol content was determined using a procedure adapted from Lorenz et al. (2000). Briefly, $50 \mathrm{mg}$ of finely powdered litter was shaken for $1 \mathrm{~h}$ with $5 \mathrm{~mL}$ of acetone/water $(70 / 30, v / v)$. After being centrifuged, $100 \mu \mathrm{L}$ of the extract was mixed with $900 \mu \mathrm{L}$ of water, $0.5 \mathrm{~mL}$ of FolinCiocalteu reagent and $2.5 \mathrm{~mL}$ of $\mathrm{Na}_{2} \mathrm{CO}_{3}$ (20\%). Polyphenol concentration was determined from a standard curve based on tannic acid at $750 \mathrm{~nm}$. The solid-state ${ }^{13} \mathrm{C}$ NMR spectra were obtained on a Bruker Avance-400 MHz NMR spectrometer operating at a ${ }^{13} \mathrm{C}$ resonance frequency of $100.7 \mathrm{MHz}$ and using a commercial Bruker double-bearing probe. About $400 \mathrm{mg}$ of sample was placed in zirconium dioxide rotors of 4-mm outer diameter and spun at the Magic Angle Spinning (MAS) rate of $10 \mathrm{kHz}$. The Cross Polarization (CP) technique was applied with a ramped $1 \mathrm{H}$-pulse starting at $100 \%$ power and decreasing to $50 \%$ during contact time ( $2 \mathrm{~ms}$ ) to avoid Hartmann-Hahn mismatches. The experiments were performed at ambient temperature and $20 \mathrm{~K}$ scans were accumulated using a delay of $2.5 \mathrm{~s}$, for an experimental time of $2 \mathrm{~h}$. The ${ }^{13} \mathrm{C}$ chemical shifts were referenced to tetramethylsilane and calibrated with glycine carbonyl signal, set at $176.5 \mathrm{ppm}$. The ${ }^{13} \mathrm{C}$ NMR spectra were divided into 7 chemical shift regions according to Dignac et al. (2002): i.e. alkyl C (0-45 ppm), methoxyl C (45-60 ppm), O-alkyl C (60-90 ppm), di-O-alkyl C (90-110 ppm), aromatic C (110-140 ppm), phenolic C (140-160 ppm) and carboxyl C (160-190 ppm). Deconvolution of each spectrum was performed on DmFit 2011 to determine the relative intensity of each selected region (Dignac et al., 2002). The aromaticity ratio (aromatic C/O alkyl C + alkyl C + aromatic C) was calculated according to Baldock et al. (1997).

\subsection{Extracellular enzyme activities}

To determine the catabolic potential of microbial communities, the activity of five extracellular enzymes (EEA) involved in soil organic carbon and phosphorus cycles were assessed: cellulase, lipase (hydrolysis), phosphomonoesterase activities. Cellulase activity was assayed using CarboxyMethylCellulose (CMC) $1 \%$ in $2 \mathrm{~mL}$ of sodium acetate buffer ( $50 \mathrm{mM}, \mathrm{pH} 6$ ) added to $0.5 \mathrm{~g}$ of soil (fresh weight) incubated for $4 \mathrm{~h}$ at $50{ }^{\circ} \mathrm{C}$. Glucose was quantified according to the Somogyi-Nelson method and absorption was read at $870 \mathrm{~nm}$ (Farnet et al., 2010a). The hydrolysis activity of lipases was measured according to Farnet et al. (2010b) using $p$-nitrophenyl laurate as substrate. Acid phosphomonoesterase was assayed using $p$-nitrophenyl phosphate monoester $(0.2 \mathrm{mM})$ in sodium acetate buffer $(100 \mathrm{mM}$, pH 4.5$)$. For both lipase and phosphomonoesterase activities, $p$-nitrophenol was quantified at $412 \mathrm{~nm}$ after the addition of $\mathrm{NaOH}(0.5 \mathrm{M})$. Enzyme activities were expressed in umoles of reaction products released per minute (U) per gram of dry soil $\left(\mathrm{U} \mathrm{g}^{-1} \mathrm{DS}\right)$.

\subsection{Microbial basal respiration and substrate-induced respiration}

Basal respiration was measured to assess the ecophysiological state of litter microbial communities. Three g DW equivalent of fresh litter was placed in $117 \mathrm{ml}$ glass jars. The glass jars were immediately sealed with hermetic rubber septa, and incubated for $4 \mathrm{~h}$ at $25^{\circ} \mathrm{C}$. After incubation, $1 \mathrm{ml}$ of air was sampled in the head space with a syringe and injected into a gas chromatograph (Chrompack CHROM 3 - CP 9001) to analyse $\mathrm{CO}_{2}$ production. The gas chromatograph was equipped with a thermal conductivity detector and a packed column (Porapack). The carrier gas helium flow was regulated at $60 \mathrm{ml} \mathrm{h}^{-1}$. Ambient $\mathrm{CO}_{2}$ concentrations were subtracted from sampled $\mathrm{CO}_{2}$ concentrations and resulting values were adjusted at $22{ }^{\circ} \mathrm{C}$ according to Ideal Gas Laws using a $\mathrm{Q}_{10}=2$.

Substrate-induced respiration (SIR) rates were estimated using a procedure from Anderson and Domsch (1978). Three grams DW equivalent of fresh litter was placed in $117 \mathrm{ml}$ glass jars and amended with powdered glucose ( $1000 \mu \mathrm{g} \mathrm{C} \mathrm{g}{ }^{-1}$ soil) found to maximize the respiration rate in our litter in a preliminary assay (data not shown). One $\mathrm{ml}$ of air was sampled in the head space with a syringe and injected into a gas chromatograph to analyse $\mathrm{CO}_{2}$ production for $1 \mathrm{~h}$ (see above). Substrate-induced respiration was converted into microbial biomass (MB) using the relation established by Beare et al. (1990). Then, the metabolic quotient $\left(\mathrm{qCO}_{2}\right)$ was obtained by calculating the $\mathrm{BR} / \mathrm{MB}$ ratio.

\subsection{Microbial C-substrate utilization profiles and catabolic diversity}

The diverse C-substrate utilization capabilities of cultivable microbial communities were determined with BIOLOG ${ }^{\circledR}$ EcoPlates (BIOLOG Inc., Hayward, CA) using a procedure adapted from Garland and Mills (1991). Briefly, $4 \mathrm{~g}$ DW equivalent of sub-sample was added to $50 \mathrm{ml}$ of sterile $0.1 \%$ Na-pyrophosphate solution ( $\mathrm{pH} 7$ ). The mixture was then shaken on an orbital shaker for $20 \mathrm{~min}$, and centrifuged at $500 \mathrm{~g}$ for $10 \mathrm{~min}$ at $4{ }^{\circ} \mathrm{C}$ to obtain a microbial suspension. Exactly $1 \mathrm{ml}$ of supernatant was diluted into $99 \mathrm{ml}$ of sterile saline solution $(0.85 \%$ $\mathrm{NaCl}$ ), hand-mixed for $30 \mathrm{~s}$. and left to stand for $10 \mathrm{~min}$. We purposely did not adjust the inoculums in order to obtain uniform cell density, instead considering the total microbial count as an inherent characteristic of the microbial communities of each mesocosm. A $125 \mu \mathrm{l}$ aliquot of the diluted solution was added to each of 96 wells in a BIOLOG® EcoPlate. Plates were incubated at $25{ }^{\circ} \mathrm{C}$ and colour formation in each well was monitored at $595 \mathrm{~nm}$ using a TECAN® spectrophotometer. Measurements were performed three times a day until average well colour development (AWCD) exceeded a value of 1.0 standardized absorbance units (i.e. 3-5 days incubation). Microbial C-use intensity was assessed as the rate of average well colour development (AWCD) calculated as follows: $\mathrm{AWCD}=\Sigma \mathrm{ODi} / 31$, where ODi is the optical density for each well in the mid-exponential growth phase (i.e. after $72 \mathrm{~h}$ ). Absorbance values for the wells with $C$ sources were blanked against the control well. The incubation time resulting in an AWCD $=0.5$ absorbance unit $\left(\mathrm{T}_{0.5}\right)$ was calculated for each sample and used to standardize the optical density of each C-containing well (Garland and Mills, 1991). Catabolic diversity was calculated using Shannon's index:

where $p_{i}$ is the ratio of colour development of the $i$ th well to the sum of colour development of all positive wells.

$$
H^{\prime}=-\sum_{i=1}^{N} p i \log _{10} p i
$$

\subsection{Effect of pre-exposure to stresses on functional resistance to added os- motic stress}

For each mesocosm, two aliquots of $1.7 \mathrm{~g}$ DW equivalent of fresh litter were placed in $117 \mathrm{ml}$ glass jars, moisture was standardized at $600 \mathrm{~g} \cdot \mathrm{kg}^{-1}$ and then jars were incubated for 2 days at $25^{\circ} \mathrm{C}$. After incubation, a first measure of basal respiration $\left(B R_{t 1}\right)$ was performed. The additional drought stress consisted of drying litter subsamples for $72 \mathrm{~h}$ at $50{ }^{\circ} \mathrm{C}$, and the additional salt stress, of an input of $10 \mathrm{mg}$ of chlorine ions $(\mathrm{NaCl})$ per $g$ of litter. After each type of stress, samples were then incubated at $25^{\circ} \mathrm{C}$ for $12 \mathrm{~h}$. A second measurement of basal respiration $\left(B R_{t 2}\right)$ was performed using the procedure described above. Resistance was calculated according the formula described by Orwin and Wardle (2004):

Resistance $=1-\frac{2 \times\left|B R_{t 2}-B R_{t 1}\right|}{B R_{t 1}+\left|B R_{t 2}-B R_{t 1}\right|}$

The RS values are bounded by -1 and +1 . An index value of 1 indicates full resistance. A value of 0 indicates either a $100 \%$ decrease or increase in $B R$ compared to the unstressed soil $\left(B R_{t 1}\right)$, and a negative index 
value indicates a change in basal respiration greater than 100\% compared to the unstressed soil (Orwin and Wardle, 2004).

\subsection{Statistical analyses}

To determine whether, and to what extent, microbial properties depended upon i) distance from the sea (coastland vs inland), ii) litter species (Cistus vs Pistacia vs mixed litter), iii) type of stress (unstressed control vs drought vs salt vs combined drought-salt stresses) and iv) their interactions, we used mixed full-factorial models for three-way ANOVA (i.e. basal respiration, substrate-induced respiration, metabolic quotient, catabolic diversity, exoenzyme activities and resistance to added stresses) with type III sums of squares, using GLM in Statistica 6.1. When necessary, data were log-transformed to meet the assumptions of normality and homogeneity of variances. When a 2-way interaction was found between stress type and distance from the sea or plant litter species, we separated data for each modality of distance from the sea or plant litter species so as to interpret the effect of stress type using a one-way ANOVA. Statistically significant $(P<0.05)$ main effects and interactions were analysed further using HSD post hoc tests.

Biolog ${ }^{\circledR}$ data were subjected to a three-factorial PERMANOVA based on Euclidean distance using Primer software v6 (Primer-E Ltd., UK) (Anderson et al., 2008). PERMANOVA eliminates the requirement for normal distribution that must be satisfied for the analysis of variance, but which is impossible to fulfil with many kinds of multivariate ecological data. Statistically significant $(\mathrm{P}<0.05)$ main effects and interactions were analysed further using pair-wise comparison tests for PERMANOVA (Anderson, 2001). Principal component analysis (PCA) was performed on covariance matrices obtained from Biolog® data to provide an ordination of the microbial C-substrate utilization profiles, which were plotted in one and two dimensions respectively, based on the scores of the first two principal components (PC). A correlation circle was computed to clarify the contribution of each C-substrate to the principal component axes.

\section{Results}

3.1. Responses of microbial activities to drought, salt and combined drought-salt stresses whatever their origin (coastal vs inland area or type of litter)

Surprisingly, after 70 days of alternate stress and non-stress periods, neither cellulase nor phosphatase activities were observed to be affected by any type of stress (Table 1 ), which is a finding of importance considering the role of such activities in organic matter turn-over. On the other hand, microbial basal respiration (BR), substrate-induced respiration (SIR) and lipase activity were significantly controlled by the type of stress (Table 1). Both salt stress and combined stresses significantly decreased BR and lipase activity, compared to control or drought stress (Fig. 1a and c). BR and lipase activity were indeed not affected by drought compared to control (Fig. 1a and c). This result revealed variations in tolerance of microbial communities depending on the type of stress and consequently that organic matter transformation can be hampered under certain conditions. Moreover, microbial biomass was significantly affected by the three type of stress as follows: control $<$ drought $=$ salt $<$ combined stresses (Fig. 1b). Therefore, considering all these results, under drought stress conditions, microbial biomass was lower compared to control but microorganisms were more active (BR after drought the same as control).

We further investigated the effects of the different types of stress on the functional diversity of litter microbial communities. Fig. 2 shows the results of principal component analysis from Biolog® data according to axes 1 and 2 (accounting for 31.2 and 19.1\% of the variance respectively). According to axis 1 , the catabolic profiles of the microbial communities from litter subjected to salt stress differ from those subjected to drought stress and combined stresses $(\mathrm{F}=3.3, \mathrm{P}<0.001)$. Differences were also found between control litters and those subjected to salt stress $(\mathrm{F}=2.6, \mathrm{P}<0.001)$, to drought stress $(\mathrm{F}=2.7, \mathrm{P}<0.001)$, and to combined stresses $(\mathrm{F}=3.1, \mathrm{P}<0.001)$ according to axis 2 . These different projections are explained by the catabolism of certain substrates: while microbial communities under drought and combined stress extensively catabolized carbohydrates such as Glucose-1-phosphate, Glucosamine and Glycerol phosphate, salt stress favoured the degradation of polymers (glycogen and Tween 80 ) and in control litter, microbial communities used organic acids as carbon sources.

\subsection{Distance from the sea and type of litter shape microbial functional re- sponses to stress}

When we examined the two litters of the plant species selected, we indeed found differences in certain chemical markers. The 'coastal print' was revealed by the electrical conductivity (EC) of the plant material: EC of litter collected from the coastal area was indeed significantly greater than from the inland area (Table 2) but did not depend on litter identity (area $\times$ litter identity interaction; F1,8 $=2.3, \mathrm{P}=0.16$ ). Table 2 also shows chemical differences depending on the plant species considered: both carbon and nitrogen contents in Pistacia litter were significantly greater than that in Cistus litter, and regardless of the distance from the sea (area $\times$ litter identity interactions; F1,8 $=0.57, \mathrm{P}=0.46$ and $\mathrm{F} 1,8=0.38, \mathrm{P}=0.55$, respectively). Consequently, $\mathrm{C}: \mathrm{N}$ ratio did not differ between litters, whatever the distance from the sea. Polyphenol content was twice as high $(\mathrm{P}<0.05)$ in Pistacia litter, which is consistent

Table 1

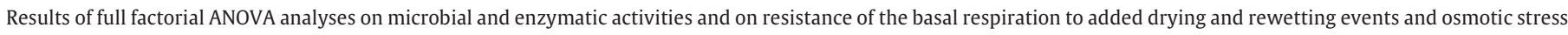
(total d.f. $=71$ ).

\begin{tabular}{|c|c|c|c|c|c|c|c|c|c|c|c|c|c|c|c|c|c|c|c|}
\hline \multirow[t]{2}{*}{$\begin{array}{l}\text { Effects } \\
\text { Stress (S) }\end{array}$} & \multirow[t]{2}{*}{$\begin{array}{l}\text { d.f. } \\
3\end{array}$} & \multicolumn{2}{|c|}{$\begin{array}{l}\text { Basal } \\
\text { respiration } \\
(\mathrm{BR})\end{array}$} & \multicolumn{2}{|c|}{$\begin{array}{l}\text { Substrate-induced } \\
\text { respiration }\end{array}$} & \multicolumn{2}{|c|}{$\begin{array}{l}\text { Metabolic } \\
\text { quotient }\end{array}$} & \multicolumn{2}{|c|}{$\begin{array}{l}\text { Lipase } \\
\text { activity }\end{array}$} & \multirow[t]{2}{*}{$\begin{array}{l}\text { Cellulase } \\
\text { activity } \\
\\
2.0\end{array}$} & \multicolumn{3}{|c|}{$\begin{array}{l}\text { Phosphomonoesterase } \\
\text { activity }\end{array}$} & \multicolumn{2}{|c|}{$\begin{array}{l}\text { Catabolic } \\
\text { diversity }\end{array}$} & \multicolumn{2}{|c|}{$\begin{array}{l}\text { Resistance } \\
\text { of BR to } \\
\text { added } \\
\text { D/Rw } \\
\text { events }\end{array}$} & \multicolumn{2}{|c|}{$\begin{array}{l}\text { Resistance } \\
\text { of BR to } \\
\text { added } \\
\text { osmotic } \\
\text { stress }\end{array}$} \\
\hline & & 31.7 & $* * *$ & 21.7 & $* * *$ & 7.9 & $* *$ & 3.8 & $*$ & & ns & 0.5 & ns & 7.1 & $* * *$ & 5.9 & ** & 3.5 & * \\
\hline Distance (D) & 1 & 2.5 & ns & 0.8 & ns & 14.1 & $* *$ & 1.8 & ns & 0.05 & ns & 1.2 & ns & 5.0 & * & 0.5 & ns & 0.01 & ns \\
\hline Litter (L) & 2 & 6.5 & $* *$ & 8.5 & $* * *$ & 0.1 & ns & 2.1 & ns & 0.8 & ns & 0.3 & ns & 4.2 & * & 1.2 & ns & 1.8 & ns \\
\hline $\mathrm{S} \times \mathrm{D}$ & 3 & 1.7 & ns & 0.5 & ns & 3.7 & * & 0.4 & ns & 1.6 & ns & 0.3 & ns & 6.0 & ** & 0.4 & ns & 3.4 & $*$ \\
\hline $\mathrm{S} \times \mathrm{L}$ & 6 & 0.8 & ns & 0.7 & ns & 0.6 & ns & 0.5 & ns & 0.7 & ns & 0.3 & ns & 1.4 & ns & 0.2 & ns & 0.2 & ns \\
\hline $\mathrm{D} \times \mathrm{L}$ & 2 & 0.2 & ns & 1.3 & ns & 4.2 & $*$ & 1.3 & ns & 0.1 & ns & 0.3 & ns & 4.2 & ns & 0.1 & ns & 0.2 & ns \\
\hline $\mathrm{D} \times \mathrm{L} \times \mathrm{S}$ & 6 & 0.6 & ns & 1.6 & ns & 2.3 & ns & 0.6 & ns & 0.4 & ns & 0.1 & ns & 1.0 & ns & 1.3 & ns & 0.9 & ns \\
\hline
\end{tabular}

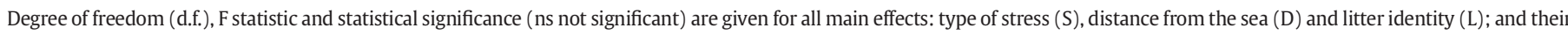
two-way and three-way interactions.

* $\mathrm{P}<0.05$.

** $\mathrm{P}<0.01$

*** $\mathrm{P}<0.001$. 
(a)

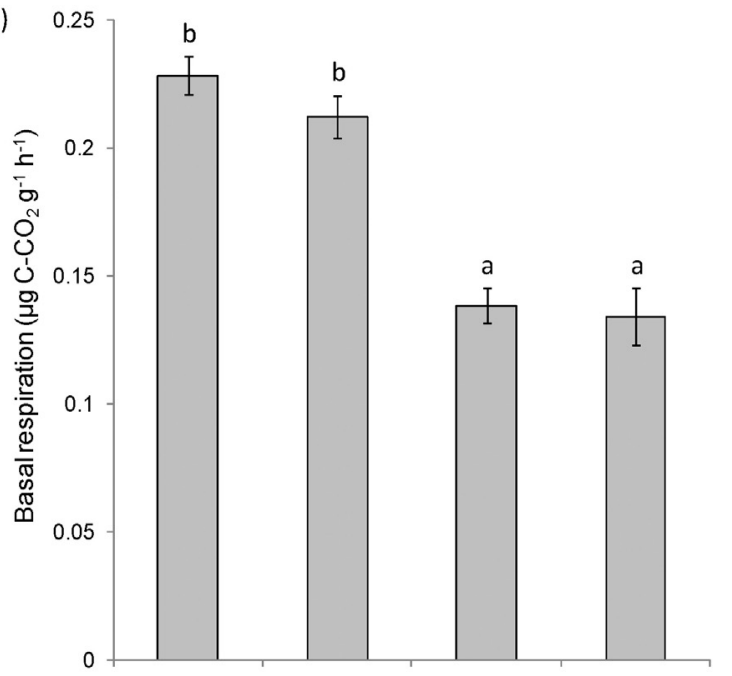

(b)
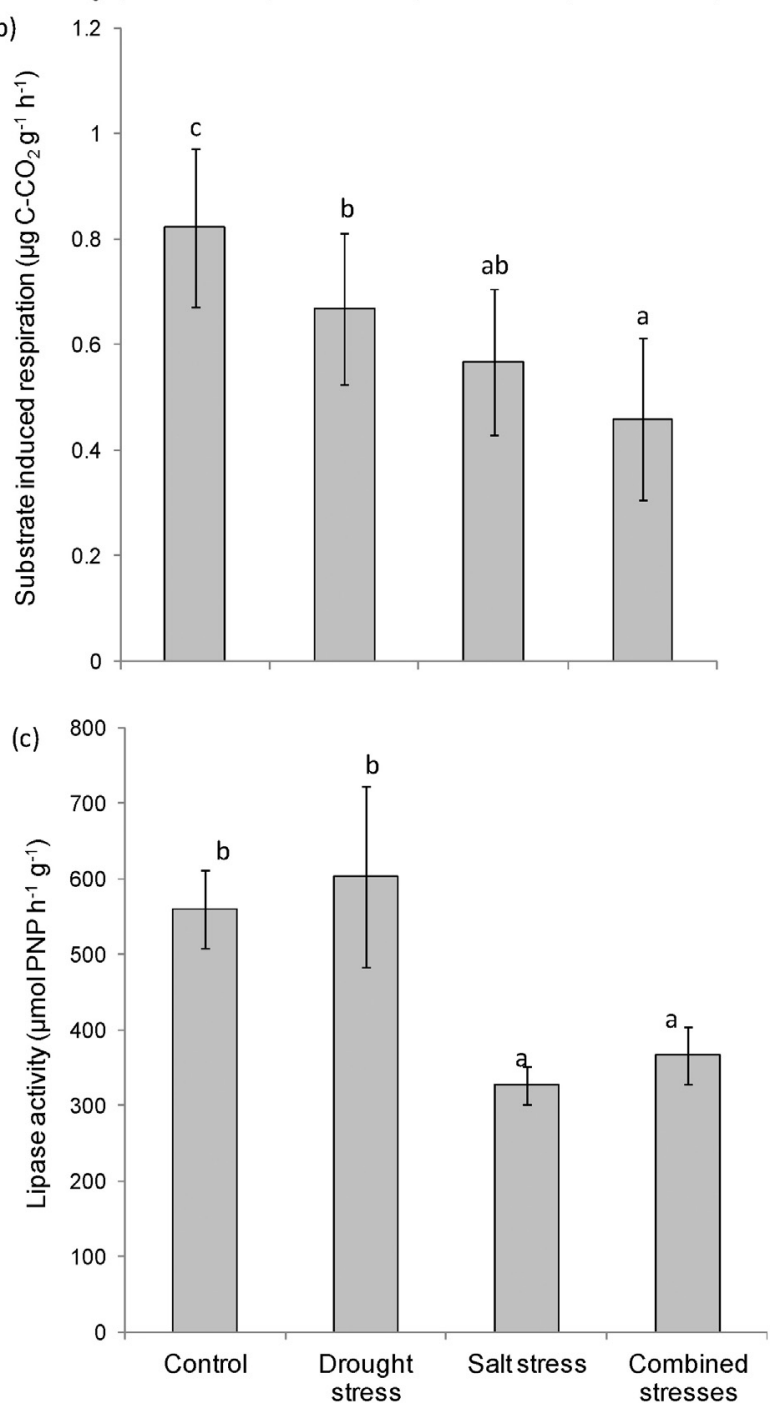

Fig. 1. Microbial basal respiration (a), substrate-induced respiration (b) and lipase activity (c) for litters (mean of Cistus albidus, Pistacia lentiscus and mixed litters) from coastal and inland area, incubated under control conditions, drought stress, salt stress and combined drought-salt stresses. Means ( \pm standard error, $N=24$ ) with the same letters are not significantly different (HSD test, $\mathrm{P}<0.05$ ).

with the results from NMR data (aromaticity ratio of 22 and $16 \%$ for Pistacia and Cistus litter respectively). Pistacia litter was thus more sclerophyllous than Cistus litter but distance from the sea had no effect

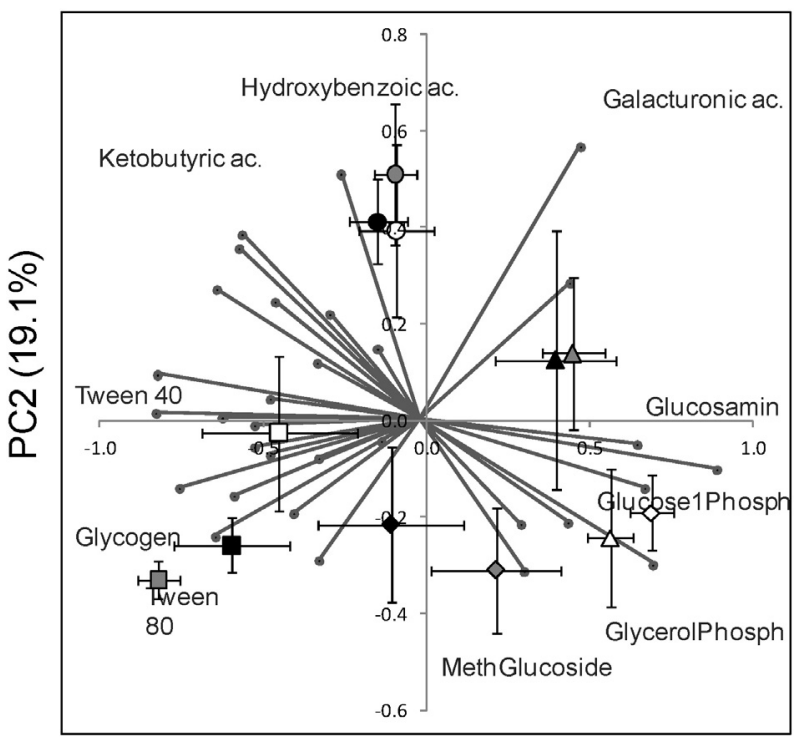

PC1 (31.2\%)

Fig. 2. Factorial Map $(\mathrm{PC} 1 \times \mathrm{PC} 2)$ with correlation circle obtained from principal component analysis on microbial C-substrate utilization profiles of Cistus albidus (white symbols), Pistacia lentiscus (black symbols) and mixed (grey symbols) litters incubated under control conditions (circles), drought stress (triangles), salt stress (squares) and combined drought-salt stresses (diamond-shape). Bars represent standard errors. Identified substrates had a correlation coefficient of 0.5 or higher (ac.: acid, Phosph.: Phosphate).

on the chemical composition of the plant species (Table 1), though stresses specific to coastal areas may have reinforced the sclerophyllous characteristics of the species as an adaptive trait.

Interestingly, concerning microbial markers, our study revealed that the effects of stresses on microbial metabolic quotient and catabolic diversity (assessed via Shannon-Weaver Index) depended on distance from the sea as described by the full factorial ANOVA (Table 1). In inland litter, no type of stress had a significant effect on metabolic quotient compared to control litter, while for coastal litter, this microbial parameter significantly decreased after combined stresses (Fig. 3a). In both coastal and inland areas, catabolic diversity did not vary from that of control, whatever the stress considered (Fig. 3b, see letters). However, after drought and combined stresses, catabolic diversity $\left(\mathrm{H}^{\prime}\right)$ was higher in litter from the coastal area than in litter from the inland area (Fig. 3b, see asterisks). This suggests that the capacity of these two microbial communities to adapt to stress depends on their origin and thus on their exposure to environmental stresses linked to water availability (desiccation, osmotic stress via sea spray exposure in the coastal area). Moreover, when $\mathrm{H}^{\prime}$ and $\mathrm{qCO}_{2}$ (Fig. 3a and b) are considered in the inland area, a catabolic diversity decrease is associated with an increase in metabolic quotient after drought and combined stresses.

Table 2

Physico-chemical and microbiological characteristics of Cistus and Pistacia litters from inland and coastal areas (mean \pm standard deviation).

\begin{tabular}{lllll}
\hline & Cistus litter & \multicolumn{3}{c}{ Pistacia litter } \\
\hline & Inland area & Coastal area & Inland area & Coastal area \\
EC $\left(\mu \mathrm{S} \mathrm{cm}^{-1}\right)$ & $65 \pm 16$ & $674 \pm 533$ & $40 \pm 2$ & $265 \pm 273$ \\
$\mathrm{TOC}(\%)$ & $52.7 \pm 1.8$ & $50.8 \pm 1.8$ & $58.4 \pm 3.3$ & $54.3 \pm 2.6$ \\
$\mathrm{TN}(\%)$ & $1.1 \pm 0.02$ & $0.9 \pm 0.2$ & $1.3 \pm 0.1$ & $1.1 \pm 0.1$ \\
$\mathrm{C}: \mathrm{N}$ & $53 \pm 2$ & $55 \pm 10$ & $47 \pm 5$ & $51 \pm 9$ \\
Polyphenol & $5.3 \pm 3.0$ & $5.6 \pm 0.8$ & $16.5 \pm 6.3$ & $13.7 \pm 5.1$ \\
$\quad$ content $\left(\mathrm{mg} \mathrm{g}^{-1}\right)$ & 16 & 16 & 22 & 21 \\
Aromaticity $(\%)$ & $0.43 \pm 0.03$ & $0.06 \pm 0.02$ & $0.28 \pm 0.07$ & $0.26 \pm 0.02$ \\
$\mathrm{BR}\left(\mu \mathrm{g} \mathrm{C}-\mathrm{CO}_{2} \mathrm{~h}^{-1} \mathrm{~g}^{-1}\right)$ & $0.08 \pm$ & $0.06 \pm$ & $0.06 \pm$ & $0.06 \pm$ \\
$\mathrm{MB}\left(\mu \mathrm{g} \mathrm{Cmic} \mathrm{g} \mathrm{g}^{-1}\right)$ & 0.004 & 0.002 & 0.005 & 0.021 \\
\hline
\end{tabular}



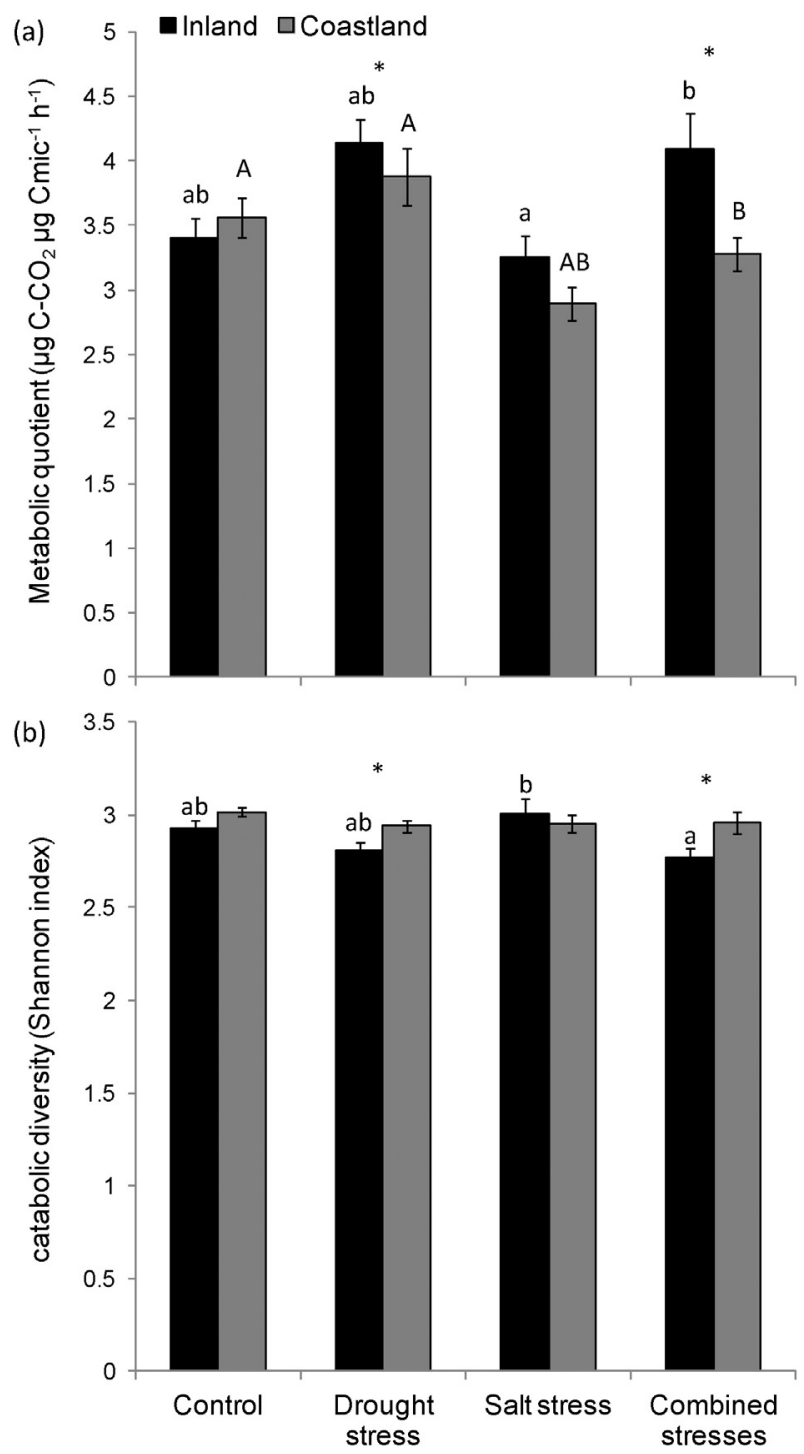

Fig. 3. Microbial metabolic quotient (a), catabolic diversity (b) and resistance of basal respiration to an added salt stress for inland and coastal litters incubated under control conditions, drought stress, salt stress and combined drought-salt stresses. Means ( \pm standard error, $\mathrm{N}=12$ ) with the same letters are not significantly different (HSD test, $\mathrm{P}<0.05)$.

Microbial basal respiration (BR), substrate-induced respiration (SIR) and catabolic diversity significantly varied with the type of litter, as shown by full factorial ANOVA with no interaction with other factors (Table 1). The principal component analysis from Biolog data clearly shows the effect of the type of litter on catabolic profiles after different stresses (Fig. 2). For controls, projections from the three types of litters are grouped together, whereas for litters subjected to different stresses, the catabolic profile of Cistus litter is separated from both those of Pistacia and of mixed litters, and this differentiation is stronger for litters subjected to drought stress. Moreover, the effect of salt stress on the catabolic profile of the microbial communities from Cistus litter is stronger than that obtained after drought stress or combined stresses.

\subsection{Effect of pre exposure to stress on resistance of basal respiration to added osmotic stress or severe drought}

We found that resistance to an additional osmotic stress was higher than that to a matric/thermic stress (Fig. 4a vs Fig. 4b) and this was observed for microbial communities in control and for those previously subjected to salt or drought stress. It has to be noted that a severe matric and thermic stress $\left(50^{\circ} \mathrm{C}\right.$ for $72 \mathrm{~h}$ ) was applied to litters, which probably explains this result. Interestingly, compared to control, the resistance of basal respiration to an added D/Rw event was higher, for microbial communities pre-exposed to combined stresses, whereas osmotic or drought stress alone did not induce such high resistance (Fig. 4a).

It is also noteworthy that the resistance of BR to an added osmotic stress strongly depended on the distance from the sea (Table 1). Compared to control, litters from the inland area showed significantly higher resistance of $B R$ to an additional osmotic stress when there had been a previous salt stress (Fig. 4b). Compared to control, litters from the inland area showed significant higher resistance of BR to an added osmotic stress when there had been a previous salt stress (Fig. 4a). However, compared to control, combined stresses hampered the resistance of BR to an added osmotic stress for litters from the coastal area. Therefore, while combined stresses selected microbial communities better adapted to severe drought, the same stresses decreased resistance to an added osmotic stress for microbial communities from coastal environments, suggesting that a threshold of tolerance to water potential stresses was reached.

\section{Discussion}

Accumulating intracellular osmolytes are known to be the main microbial response to salt or drought stress. Though this physiological process of adaptation is common to both stresses, we wanted to determine how metabolism may be influenced by such events and thus whether microbial activities (assessed via different markers), microbial biomass and catabolic diversity may vary depending on the type of stress considered and a pre-exposure to similar stresses (for litters from either coastal or inland areas).

First, it has to be noted that, in our study, drought stress involved drying/rewetting events (thus including variations in $a_{w}$ ) as a common experimental design to assess drought stress, while $\mathrm{NaCl}$ solution was applied onto the litter at the beginning of the experiment (constant $a_{w}$ throughout the experiment). Thus, through this experimental design mimicking environmental conditions of stress, the microbial responses observed for these two types of stress has an ecological relevance. When considering the effect of the different stresses whatever the origin or the type of litter, we found that BR and lipase activity were affected conversely to cellulases and phosphatases. The influence of moisture on exocellular enzyme activities greatly depended on their rate of production and their stability after excretion: the more rapidly enzymes are degraded (mainly depending on their structure and their adsorption onto soil particles or organic compounds such as humic substances), the more important production rate is in sustaining microbial activities (Burns, 1982). Moreover, these contrasting results between microbial markers can perhaps be explained by the differing quantities of water used to measure microbial activities. For cellulase and phosphatase activities, we measured potential activities with a huge quantity of water by adding buffers. These standard experimental conditions commonly used to measure cellulase and phosphatase activities may enhance microbial responses and thus reduce the effect of stresses. When measuring BR, SIR and lipase activities, a very small quantity of water was added to the litter compared to the assays for cellulase and phosphatase activities. For BR and SIR, measurements were performed at $60 \%$ moisture, and for lipase activities an apolar solvent, heptane, was added to a small quantity of water (Farnet et al., 2013). Thus, under these conditions, lower water content may have limited interactions between enzymes and their substrate. This suggests that certain microbial indicators such as BR, involving small quantities of water, may more clearly reveal the effect of certain stresses and reflect the 'real' in situ interaction between enzymes and their substrates in the sample (Farnet et al., 2013).

For salt and combined stresses, a decrease in both microbial biomass and activities was observed, revealing that these stresses have a massive impact on microbial communities. Chowdhury et al. (2011b) propose 

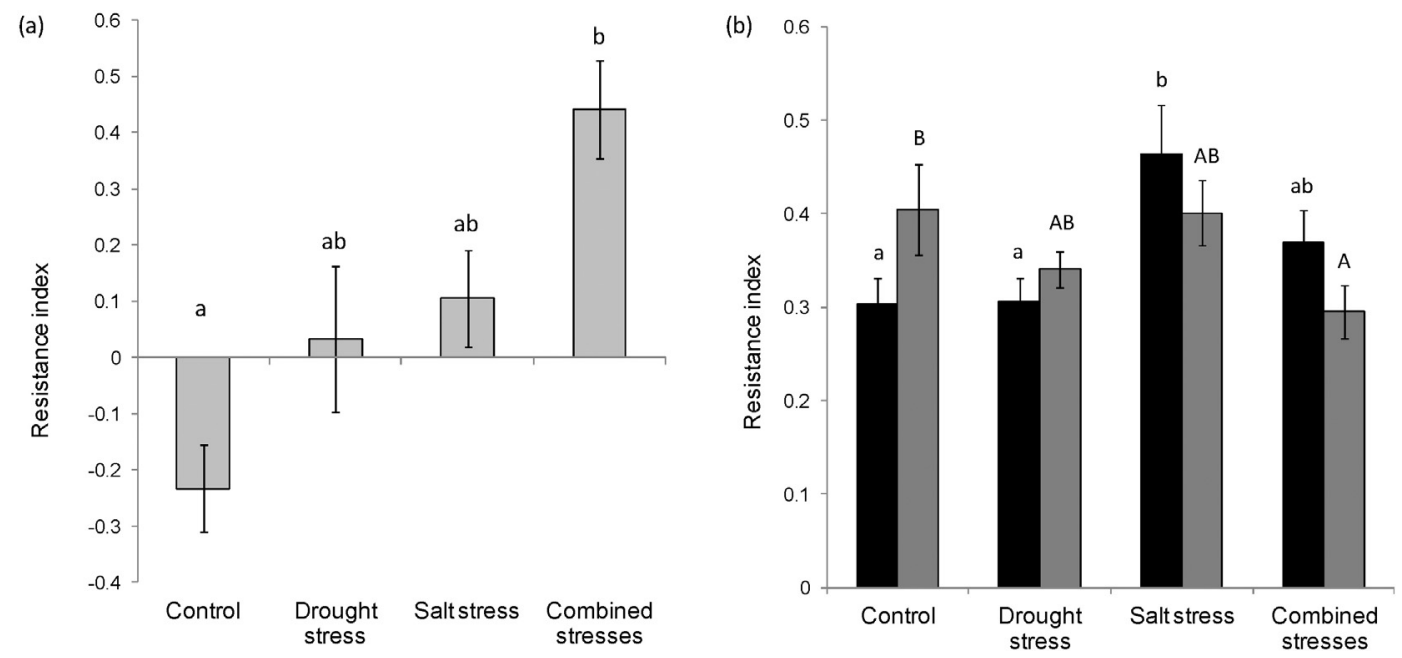

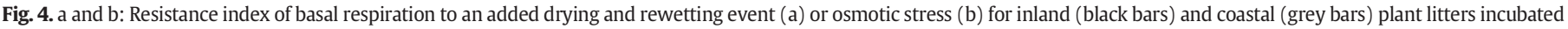

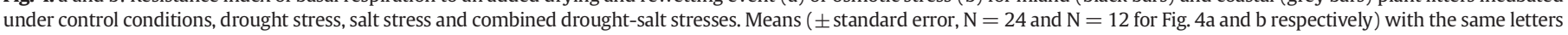
are not significantly different (HSD test, $\mathrm{P}<0.05$ ).

that microbial response varies depending on water potential (WP): when WP decreases, certain microorganisms survive and respiration per unit of biomass remains constant, while, above a certain WP threshold ( $-2 \mathrm{MPa}$, in the case of sandy soils according to Chowdhury et al., 2011a), adaptation is not effective enough and both biomass and microbial activity drastically decrease. This latter appears to be the case in our study, for both salt stress and combined stresses. Concerning this relative sensitivity to varying stresses, few previous studies have looked closely at how microorganisms cope with low WP due to either drought or salt stress. Kakumanu and Williams (2014) have shown that WP deficit due to salt stress has a stronger effect on microbial communities, mainly on the following proxy: biomass, fungi to bacteria ratio and structure (assessed via PLFA). The different shifts in microbial populations due to osmotic or matric stress respectively, explain the varying functional and physiological responses observed, mainly differences in the type of osmolytes produced and in microbial respiration. The authors observed a higher decrease in respiration when low WP was due to drought rather than to osmotic stress, which is in accordance with Chowdhury et al. (2011a). In this latter study, the authors obtain the same WP for higher water content in saline soils than in non-saline soils, since water molecules are bound to salts. Thus, the lack of available water due to drought limits microorganism motility and consequently nutrient allocation, which may not be the case under osmotic stress, where moisture is higher. In our study, microbial markers were quantified from mesocosms incubated for 15 days at $600 \mathrm{~g} \cdot \mathrm{kg}^{-1}$ water content and $25{ }^{\circ} \mathrm{C}$ : thus, although the quantity of water $\left(600 \mathrm{~g} \cdot \mathrm{kg}^{-1}\right.$ water content) was the same in mesocosms subjected to osmotic stress, $\mathrm{NaCl}(10 \mathrm{mg} / \mathrm{g}$ of litter) induced a lower WP. This may also explain why we found a higher impact of osmotic stress than of drought stress on microbial markers, as previously demonstrated by Kakumanu and Williams (2014). However, here, we wanted to assess microbial responses after either osmotic or drought stress under the most favourable conditions of water content $\left(600 \mathrm{~g} \cdot \mathrm{kg}^{-1}\right)$ recorded in the litter sampling area (Qasemian et al., 2014).

Interestingly, the effects of combined stresses were the same as those of osmotic stress alone on biomass, BR or lipases. This means that although the $a_{w}$ reached for combined stresses was lower $\left(a_{w}=\right.$ 0.7 ) than that reached for either drought or osmotic stress $\left(a_{w}=0.8\right)$, it led to the same microbial responses. Thus our study reveals that the nature of the stress seems to be also of major importance in the way microbial communities are able to cope with stress linked to water availability. It would be valuable to define the threshold of tolerance to matric stresses in litters. As stated by Rath and Rousk (2015), determining such a threshold is methodologically complex (choice of microbial markers, time of exposure consider), which makes it difficult to perform an accurate assessment as the kind used to determine the toxic effects of metallic or organic pollutants.

We also found out that the three types of stress structured differently microbial catabolic profiles. Stresses linked to water availability are known to strongly alter microbial community functions and diversity. Pankhurst et al. (2001) used both FAME and catabolic patterns to show a shift in microbial communities from a forest soil exposed to saline stress towards bacterial-dominant microbial communities. Marinari et al. (2012) also used functional indicators of diversity to investigate the effects of saline environments on microbial enzyme activities, revealing that saline soils favoured the functional diversity of microbial communities.

Thus, this study revealed that the impact of these different stresses varied depending on the microbial markers considered. Indicators of microbial activities and biomass were similarly affected by salt stress and combined stresses while drought had a lesser effect. In contrast, catabolic profiles were similarly affected by drought and combined stresses with salt stress structuring communities microbial differently.

We hypothesised that microbial responses to stresses linked to water availability may be strongly influenced by coastal environment (sea spray exposure, wind regime leading to more intense desiccation) or litter organic matter, since these two sets of environmental conditions may have shaped microbial communities differently. The influence of the coastal environment is actually observable via litter chemical characteristics, as shown by the higher EC found in litters from this zone. As described in our previous study (Qasemian et al., 2014), we showed that EC in litters from coastal areas was correlated to chlorine concentration, which can be considered as a marker of sea sprays. The influence of the 'coastal print' on microbial responses to stress was revealed via certain microbial markers i.e. $\mathrm{H}^{\prime}$ and $\mathrm{qCO}_{2}$. A catabolic diversity decrease was associated with an increase in metabolic quotient after drought and combined stresses in the inland area. Moreover, $\mathrm{H}^{\prime}$ of litters from coastal area was higher after drought and combined stress. This findings support the assumption that microbial communities from inland areas are less adapted to these stresses than those in coastal areas since a decrease in microbial diversity hampers soil functioning (Rivest et al., 2013). Thus matric and osmotic stresses, specific to coastal areas, may have shaped microbial communities differently from those in inland areas, as found in previous studies. Contrasting results have been found concerning stress responses of microbial communities from stressed or non-stressed environments. Asghar et al. (2012), when investigating variations in microbial community composition and activities, found that microorganisms from saline or non- 
saline soils responded similarly to changes in salinity. Wichern et al. (2006) observed that microbial communities from saline soil were more tolerant to high salt concentrations and were more efficient in plant material degradation. Concerning matric stress, Fierer et al. (2003) showed that microbial communities from grassland, subjected to more intense changes in water potential than those in forest soils, were less drastically impacted in their community structure after drying/rewetting events. In our study, litters sampled in a coastal area had been subjected to saline stress probably due to variations in sea spray exposure impacting the litter over time: Qasemian et al. (2014) monitored electrical conductivity in a coastal litter over a one-year period and found that it varied greatly seasonally. These fluctuations in salt concentrations may well be more stressful than constant high osmotic stress and may also play a key role in structuring microbial communities to cope with this type of stress.

Our results also highlight the importance of the quality of organic matter on microbial responses: here, the recalcitrant fraction of organic matter strongly influences microbial functions as revealed by the similar diversity patterns obtained for both Pistacia and mixed litters compared to that of Cistus. Keith et al. (2008) or Rodríguez-Loinaz et al. (2008)clearly demonstrated that litter species diversity strongly influences the stability of decomposer communities via the diversity of soil resources. Similarly, Rajaniemi and Allison (2009) found, across a transect away from the sea shore, that biomass depended on the presence and type of vegetation (soil carbon inputs via plant detritus and root exudates depending on the species), and that both community composition and biomass were strongly influenced by distance from the coast (direct effect of sea sprays on soil salinity and indirect effect of vegetation, which can result in lower soil temperatures, wind speed or sand accretion). Clearly, these different factors acting at various scales to drive soil functioning, particularly microbial responses to stresses, need to be taken into account.

In this study, we also examined whether the origin of litter may influence microbial responses to additional stresses (additional severe drought or osmotic stress). The potential of microorganisms to adapt to stresses is known to be conditioned by both microbial community composition and the stress legacy of their environment (Rath and Rousk, 2015). Most studies have focused on responses of microbial communities from saline environments when evaluating how pre exposure to stress may influence microbial functioning in response to added stresses. Here, we hypothesised that i) microbial communities previously subjected to stresses would show greater basal respiration resistance to added experimental stresses ii) this resistance would be more intense for microbial communities in litter from coastal areas, which have probably been structured by the environmental conditions specific to this zone. Here, we found that microbial communities pre-exposed to combined stresses were more resistant to severe drought, whereas stress applied alone did not result in such potential of resistance. Inversely, Berard et al. (2012) observed that microbial communities exposed to drought appeared to be more resistant to a subsequent drought and heat disturbance, suggesting that the microbial adaptations responsible for drought tolerance are related to those for heattolerance. Mediterranean soils, which are frequently exposed to water shortage, are known to harbour microorganisms that have adapted to respond quickly to water availability (Collins et al., 2008). In our study, the combination of drought and salt stresses probably reinforced the capacity of these microbial communities to withstand the D/Rw events applied, by selecting microorganisms better able to maintain respiration.

Interestingly, basal respiration of litters from inland area exhibit a better resistance to additional osmotic stress when there had been a pre exposure to the same type of stress. Here again, the first salt stress probably favoured the capacity of these microbial communities to withstand the second osmotic stress applied. Thus our results clearly indicated that basal respiration resistance can be ensured when different microbial communities are shaped to resist different stresses. However, our experiment also showed that basal respiration of litter from coastal area pre exposed to combined stresses, decreased after the additional osmotic stress. Previous studies indicated that microbial communities from stressed environments might be more impacted by an added stress (Griffith et al., 2000). Thus, these contrasted findings here raised the particularly complex question of determining the threshold of resistance in microbial functioning under extreme conditions.

\section{Conclusion}

Most soil microorganisms are known to have genetic resources enabling them to resist stresses such as high temperatures, drought, osmotic potential which can explain their resistance to variations in environmental conditions. It is important to distinguish the respective effects of osmotic stress, of drought and of their interaction on microbial functioning. In our study, when combined, matric and osmotic stresses did not lead to synergistic effects on microbial functioning. Moreover, the chemical composition of litters had only a minor effect on microbial responses to stresses. Environmental conditions in coastal areas can actually be considered as a major factor driving microbial functioning and adaptation to stresses linked to water potential. Disentangling the various environmental factors (type of soil and litter, geographical location, stress legacy) driving microbial responses to osmotic and/or matric stresses at various spatial scales is of huge importance in the effort to understand Mediterranean ecosystem functioning in changing environments.

\section{Acknowledgements}

We would like to thank Marjorie Sweetko for the English language revision. This study was supported by Aix Marseille Université.

We would like to thank the editor, both reviewers and Dr I. LaffontSchwob (Institut Méditerranéen de Biodiversité et d'Ecologie, Aix Marseille Université) for the review of this work and their precious suggestions.

\section{References}

Anderson, J.P.E., Domsch, K.H., 1978. A physiological method for quantitative measurement of microbial biomass in soils. Soil Biol. Biochem. 10, 215-221.

Anderson, M.J., Gorley, R.N., Clarke, K.R., 2008. PERMANOVA for PRIMER: Guide to Software and Statistical Methods. PRIMER-E, Plymouth, UK.

Asghar, H.N., Setia, R., Marschner, P., 2012. Community composition and activity of microbes from saline soils and non-saline soils respond similarly to changes in salinity Soil Biol. Biochem. 47, 175-178.

Baldock, J.A. Oades, J.M., Preston, C.M., Nelson, P.N., Skene, T.M., Golchin, A, Clark, P. 1997. Assessing the extent of decomposition of natural organic materials using solide state ${ }^{13} \mathrm{C}$ NMR spectroscopy. Aust. J. Soil Res. 35, 1061-1083.

Beare, M.H., Neely, C.L., Coleman, D.C., Hargrove, W.L., 1990. A substrate induced respiration ( $\mathrm{sir}$ ) method for measurement of fungal and bacterial biomass on plant residues. Soil Biol. Biochem. 22, 585-594.

Berard, A., Bouchet, T., Dorigo, U., Sevenier, G., Pablo, A.L., Gros, R., 2011. Resilience of soil microbial communities impacted by severe drought and high temperature in the context of Mediterranean heat-waves. Eur. J. Soil Biol. 47, 333-342.

Berard, A., Ben Sassi, M., Renault, P., Gros, R., 2012. Severe drought-induced community tolerance to heat wave. An experimental study on soil microbial processes. J. Soils Sediments 12, 513-518.

Borken, W., Matzner, E., 2009. Reappraisal of drying and wetting effects on C and mineralization and fluxes in soils. Glob. Chang. Biol. 15, 808-824.

Burns, R.G., 1982. Enzymic activity in soil: location and a possible role in microbial ecology. Soil Biol. Biochem. 14, 423-427.

Butterly, C.R., Bunemenn, E.K., McNeill, A.M., Baldock, J.A., Marschner, P., 2009. Carbon pulses but not phosphorus pulses are related to decrease in microbial biomass during repeated dring and rewetting of soils. Soil Biol. Biochem. 41, 1406-1416.

Chowdhury, N., Marschner, P., 2011. Response of microbial activity and community structure to decreasing soil osmotic and matric potential. Plant Soil 344, 241-254.

Chowdhury, N., Marschner, P., Burns, R.G., 2011a. Soil microbial community composition: impact of changes in matric and osmotic potential. Soil Biol. Biochem. 43, 1229-1236.

Chowdhury, N., Nakatani, A.S., Raj, S., Marschner, P., 2011b. Microbial activity and community composition in saline and non saline soils exposed to multiple drying and rewetting events. Plant Soil 348, 103-113.

Collins, S.L., Sinsabaugh, R.L., Crenshaw, C., Green, L., Porras-Alfaro, A., Stursova, M., Zeglin, L.H., 2008. Pulse dynamics and microbial processes in aridland ecosystems. J. Ecol. 96 413-420. 
Coûteaux, M.M., Bottner, P., Berg, B., 1995. Litter decomposition, climate and litter quality. Trends Ecol. Evol. 10, 63-66.

Dignac, M.F., Knicker, H., Kögel-Knabner, I., 2002. Effect of N content and soil texture on the decomposition of organic matter in forest soils as revealed by solid-state CPMAS NMR spectroscopy. Org. Geochem. 33, 1715-1726.

Farnet, A.M., Qasemian, L., Gil, G., Ferré, E., 2013. The importance of water availability in the reaction equilibrium of hydrolases in forest litters from a Mediterranean area: a study on lipases. Eur. J. Soil Sci. 64, 1-6.

Farnet, A.M., Qasemian, L., Goujard, L., Gil, G., Guiral, D., Ruaudel, F., Ferré, E., 2010a. A modified method based on p-nitrophenol assay to quantify hydrolysis activities of lipases in litters, soil biol. Biochemistry 42, 386-389.

Farnet, A.M., Qasemian, L., Guiral, D., Ferré, E., 2010b. A modified method based on arsenomolybdate complex to quantify cellulase activities: application to litters. Pedobiologia 53, 159-160.

Fierer, N., Schimel, J.P., Holden, P.A., 2003. Influence of drying-rewetting frequency on soil bacterial community structure. Microb. Ecol. 45, 63-71.

Fioretto, A., Papa, S., Pellegrino, A., Fuggi, A., 2007. Decomposition dynamics of Myrtus communis and Quercus ilex leaf litter: mass loss, microbial activity and quality change. Appl. Soil Ecol. 36, 32-40.

Fioretto, A., Papa, S., Pellegrino, A., Ferrigno, A., 2009. Microbial activities in soils of a Mediterranean ecosystem in different successional stages. Soil Biol. Biochem. 41, 2061-2068.

García-Fayos, P., Verdú, M., 1998. Soil seed bank, factors controlling germination and establishment of a Mediterranean shrub: Pistacia lentiscus L. Acta Oecol. 19, 357-366.

Garland, J., Mills, A., 1991. Classification and characterization of heterotrophic microbial communities on the basis of patterns of community-level sole-carbon-source utilization. Appl. Environ. Microbiol. 57, 2351-2359.

Griffith, B.S., Ritz, K., Bardgett, R.D., Cook, R., Christensen, S., Ekelund, F., Sorensen, S.J. Baath, E., Bloem, J., de Ruiter, P.C., Dolfing, J., Nicolardot, B., 2000. Ecosystem response of pasture soil communities to fumigation-induced microbial diversity reductions: an examination of the biodiversity-ecosystem function relationship. Oikos 90, 279-294.

Hättenschwiler, S., Tiunov, A.V., Scheu, S., 2005. Biodiversity and litter decomposition in terrestrial ecosystems. Annu. Rev. Ecol. Evol. Syst. 36, 191-218.

IUSS Working Group WRB, 2006. World Reference Base for Soil Resources 2006. World Soil Resources Reports No. 103. FAO, Rome, Italy.

Kakumanu, M.L., Cantrell, C.L., Williams, M.A., 2013. Microbial community response to varying magnitudes of desiccation in soil: a test of the osmolyte accumulation hypothesis. Soil Biol. Biochem. 57, 644-653.

Kakumanu, M.L., Williams, M.A., 2014. Osmolyte dynamics and microbial communities vary in response to osmotic more than matric water deficit gradients in two soils. Soil Biol. Biochem. 79, 14-24.

Keith, A.M., van der Wal, R., Brooker, R.W., Osler, G.H.R., Chapman, S.J., Burslem, D.F.R.P., Elston, D.A., 2008. Increasing litter species richness reduces variability in a terrestrial decomposer system. Ecology 89, 2657-2664.

Lorenz, K., Preston, C.M., Raspe, S., Morrison, I.K., Feger, K.H., 2000. Litter decomposition and humus characteristics in Canadian and German spruce ecosystems: information from tannin analysis and 13C CP MAS NMR. Soil Biol. Biochem. 32, 779-792.
Marinari, S., Carbone, S., Vittori Antisarib, L., Grego, S., Vianello, G., 2012. Microbial activity and functional diversity in Psamment soils in a forested coastal dune-swale system. Geoderma 173-174, 249-257.

Nannipieri, P., Ascher, J., Ceccherini, M.T., Landi, L., Pietramellara, G., Renella, G., 2003. Microbial diversity and soil functions. Eur. J. Soil Sci. 54, 655-670.

Oliveira, G., Peñuelas, J., 2000. Comparative photochemical and phenomorphological responses to winter stress of an evergreen (Quercus ilex L.) and a semi-deciduous (Cistus albidus L.) Mediterranean woody species. Acta Oecol. 21, 97-107.

Orwin, K., Wardle, D., 2004. New indices for quantifying the resistance and resilience of soil biota to exogenous disturbances. Soil Biol. Biochem. 36, 1907-1912.

Pankhurst, C.E., Yu, S., Hawke, B.G., Harch, B.D., 2001. Capacity of fatty acid profiles and substrate utilization patterns to describe differences in soil microbial communities associated with increased salinity or alkalinity at three locations in South Australia. Biol. Fertil. Soils 33, 204-217.

Papa, S. Pellegrino, A., Fioretto, A. 2008. Microbial activity and quality changes during decomposition of Quercus ilex leaf litter in three Mediterranean woods. Appl. Soil Ecol. 40, 401-410.

Pons, A., Quézel, P., 1998. À propos de la mise en place du climat méditerranéen. CRASLife Sciences. 327, pp. 755-760.

Qasemian, L., Guiral, D., Farnet, A.M., 2014. How do microlocal environmental variations affect microbial activities of a Pinus halepensis litter in a Mediterranean coastal area? Sci. Total Environ. 496, 198-205.

Rajaniemi, T.K., Allison, V.J., 2009. Abiotic conditions and plant cover differentially affect microbial biomass and community composition on dune gradients. Soil Biol. Biochem. 41, 102-109.

Rath, K.M., Rousk, J., 2015. Salt effects on the soil microbial decomposer community and their role in organic carbon cycling: a review. Soil Biol. Biochem. 81, 108-123.

Rivest, D., Lorente, M., Olivier, A., Messier, C., 2013. Soil biochemical properties and microbial resilience in agroforestry systems: effects on wheat growth under controlled drought and flooding conditions. Sci. Total Environ. 463-464, 51-60.

Rodríguez-Loinaz, G., Onaindia, M., Amezaga, I., Mijangos, I., Garbisu, C., 2008. Relationship between vegetation diversity and soil functional diversity in native mixed-oak forests. Soil Biol. Biochem. 40, 49-60.

Sardans, J., Penuelas, J., 2005. Drought decreases soil enzyme activity in a Mediterranean Quercus ilex L. forest. Soil Biol. Biochem. 37, 455-461.

Sardinha, M., Müller, T., Schmeisky, H., Joergensen, R.G., 2003. Microbial performance in soils along a salinity gradient under acidic conditions. Appl. Soil Ecol. 23, 237-244.

Schimel, J.P., Balser, T.C., Wallenstein, M., 2007. Microbial stress response physiology and its implications for ecosystem functions. Ecology 88, 1386-1394.

Yuste, J.C., Penuelas, J., Estiarte, M., Garcia-Mas, J., Mattana, S., Ogaya, R., Pujol, M., Sardan, J., 2011. Drought-resistant fungi control soil organic matter decomposition and its response to temperature. Glob. Chang. Biol. 17, 1475-1486.

Wehtje, E., Costes, D., Adlercreutz, P., 1997. Enantioselectivity of lipases: effects of water activity. J. Mol. Catal. B Enzym. 3, 221-230.

Wichern, J., Wichern, F., Joergensen, R.G., 2006. Impact of salinity on soil microbial communities and the decomposition of maize in acidic soils. Geoderma 137, 100-108.

Anderson, M.J., 2001. A new method for non-parametric multivariate analysis of variance. Aust. Ecol. 26, 32-46. 